\title{
Teletandem: enfoque na forma e o desenvolvimento do professor de língua estrangeira
}

\section{Teletandem: Focus on Form and the Development of the Foreign Language Teacher}

\author{
Aline Mara Fernandes \\ Universidade Estadual Paulista (UNESP), Assis, São Paulo, Brasil. \\ alinemaraf@yahoo.com.br \\ João Antonio Telles \\ Universidade Estadual Paulista (UNESP), Assis, São Paulo, Brasil. \\ tellesjoao@uol.com.br
}

Resumo: Teletandem é um contexto virtual, autônomo e colaborativo, com webcam (imagem, voz e texto), no qual dois estudantes ajudam um ao outro na aprendizagem de suas respectivas línguas nativas (ou de proficiência), por meio da colaboração intercultural e linguística online. Neste trabalho, voltamos nossa atenção para episódios com enfoque na forma durante uma interação de teletandem em português. Os participantes foram uma aluna brasileira (professora pré-serviço de inglês) e seu parceiro americano (um aluno universitário de português). A análise dessa interação consistiu na procura de episódios incidentais com enfoque na forma (aqueles que surgiam a partir de conversa espontânea ou que não eram previamente definidos pelos parceiros de teletandem). A análise revelou (a) a prevalência do enfoque na forma centrado no léxico, e (b) quatorze ações colaborativas entre os parceiros que proporcionaram momentos de explicações sobre vocabulário. Concluímos o trabalho com uma discussão acerca do uso da metalinguagem pelos professores; no caso deste estudo, ao ensinarem Português como Língua Estrangeira. 
Palavras-chave: Enfoque na forma; Formação de professores de línguas; Teletandem; Português-língua estrangeira.

\begin{abstract}
Teletandem is a virtual autonomous webcam-based context (image, voice and text), where two students help each other learn their native (or other) language through intercultural and linguistic collaboration. In this paper, we turned our attention to episodes of focus on form during a teletandem interaction in Portuguese. The participants were a Brazilian student (a pre-service teacher of English) and her American teletandem partner (a university student of Portuguese). The analysis of this interaction consisted in looking for focus on form episodes that were incidental (they emerged from conversation spontaneously or they were not previously defined by the teletandem partners). The analysis revealed (a) the prevalence of the focus on form concerning lexicon treatment; and (b) fourteen collaborative actions that provided moments of vocabulary explanation between the partners. We conclude with a discussion on teachers' use of metalanguage; in the case of this study, when teaching Portuguese as a foreign language.
\end{abstract}

Keywords: Focus on form; Teletandem; Foreign language teacher development; Portuguese as a foreign language.

Recebido em 13 de dezembro de 2013. Aprovado em 14 de abril de 2014.

\title{
Introdução
}

A realidade na qual vivemos é marcada por mudanças rápidas e que exigem novas formas de comunicação global, ou seja, a interação entre as pessoas precisa ser realizada por meio de ferramentas inovadoras que superem os limites de tempo e de espaço.

No âmbito educacional, novas ferramentas de interação via meios digitais, de maneira síncrona ou assíncrona, promovem novos meios de ensinar e aprender a partir do encurtamento das distâncias entre os aprendizes e entre estes e o conhecimento. $\mathrm{O}$ ensino tende a ser menos centrado no professor e mais voltado para a interação e para o diálogo 
entre aprendizes e professores. A colaboração se torna uma palavra-chave nessa nova concepção de aprendizagem. Para Braga (2007), essa nova prática de construção de saberes é mais democrática, já que as escolhas envolvidas no processo são feitas em interação e não por imposição. Nessa perspectiva, professor e aluno assumem novos papéis na coconstrução do conhecimento. O modelo tradicional de ensino, no qual o professor é detentor do saber e responsável pelo controle das interações em sala de aula e o aluno, um mero receptor, já não representa o tipo de relação estabelecida entre aluno e professor nos contextos de ensino e aprendizagem atuais, especialmente no que diz respeito à aprendizagem colaborativa em meios digitais.

Em meios virtuais de aprendizagem, o conceito de telecolaboração, conforme foi definido por Belz (2002), refere-se à aplicação de redes de comunicação global à formação e à aprendizagem de língua estrangeira (doravante LE). Em atividades telecolaborativas "são levados em conta aspectos diversos, como as intenções, os propósitos e as reflexões dos aprendizes, vistos como pessoas capazes de agir no mundo, sendo (inter) agentes de ações sociais" (KANEOYA, 2008, p. 124).

Frente às novas concepções de ensino e aprendizagem de línguas instauradas pelo uso dos meios digitais, a formação docente envolve fatores diversos os quais vão desde as configurações do contexto social e institucional até a organização curricular, passando por visões e crenças sobre ensino e aprendizagem, educação e papel do professor e do aluno. Há, ainda, muito a ser discutido e pesquisado em relação à formação do professor para atuar competentemente nos atuais contextos colaborativos de aprendizagem online (TELLES, 2009). Entre as questões a serem abordadas sobre esses contextos estão aquelas introduzidas pelas Diretrizes Curriculares Nacionais de 2002, de acordo com as quais a formação do professor deve incluir, entre outros aspectos, a preparação do docente para o uso das tecnologias da informação e comunicação e de metodologias, estratégias e materiais de apoio inovadores (Resolução $\mathrm{CNE} / \mathrm{CP} \mathrm{n}^{\mathrm{o}} 1$, de 18 de fevereiro de 2002, art. $2^{\circ}$, inciso VI). Sendo assim, o teletandem, além de ser uma ferramenta tecnológica para comunicação e troca de informações entre aprendizes e entre professores e aprendizes, configura-se como um meio que exige o desenvolvimento de novas metodologias de ensino para atender às especificidades desse contexto e às necessidades de aprendizes fisicamente distantes. Nascem novas práticas sociais e novos usos da linguagem que requerem do 
professor o desenvolvimento de habilidades cognitivas e práticas de modo a se alinharem às habilidades de uso das tecnologias digitais que são praticamente inatas às novas gerações.

Como foi levantado por Funo (2011), a partir dos estudos de Sontag (2010), o letramento digital dos docentes é necessário para que

[...] (a) não se acentue o distanciamento entre a realidade docente e discente frente às novas tecnologias de interação e comunicação e (b) se reflita sobre as vantagens que o uso desses recursos pode trazer para a aprendizagem significativa da geração mais acostumada ao uso das novas tecnologias em seu cotidiano (FUNO, 2011, p. 31).

Neste trabalho, em linhas gerais, são tratadas questões relacionadas à formação do professor de línguas no contexto do Projeto Teletandem Brasil (TELLES, 2006; 2009), um contexto virtual, autônomo e colaborativo de aprendizagem de línguas à distância.

A aprendizagem de línguas in-tandem, além de ser um meio alternativo, autônomo e colaborativo, constitui um contexto inovador para o tratamento de questões relacionadas à formação profissional de futuros professores de línguas. Além disso, as práticas interativas no teletandem abrem possibilidades reais de implementação das tecnologias na formação do professor de línguas e nos cursos de Letras. Constitui, também, um exercício de compreensão das manifestações culturais das línguas aprendidas, como preveem as Diretrizes Curriculares Nacionais para a Formação de Professores (BRASIL, 2002).

As atividades atualmente desenvolvidas no teletandem incluem: (a) sessões de orientação; (b) sessões de interação entre falantes de duas línguas distintas; e (c) sessões de mediação. Ministradas aos grupos estrangeiro e brasileiro, antes das parcerias terem início (CANDIDO, 2010), as sessões de orientação (com duração de 60') objetivam apresentar aos grupos certas estratégias de aprendizagem, estabelecimento de objetivos e explicitação clara (ao parceiro) das habilidades linguísticas que se deseja desenvolver. Já as sessões de interação têm duração de 60' (30' em cada uma das línguas), nas quais dois interagentes conversam sobre assuntos diversos, por eles preestabelecidos ou decididos no momento da interação, podendo ser um desses assuntos aspectos específicos das línguas-alvo. Finalmente, as sessões de mediação são momentos que se seguem às interações em teletandem, frequentemente 
com duração de $30^{\prime}$. A atividade de mediação permite aos envolvidos refletir sobre as experiências de ensino e aprendizagem, especialmente em relação às experiências via novos meios digitais e à distância. As sessões de mediação são desenvolvidas por cada professor, com seu grupo de alunos, em seu país, preferencialmente na língua-alvo. Nelas, os interagentes têm a oportunidade de dialogar e trocar experiências com um mediador - um professor de línguas estrangeiras ou mesmo um futuro professor (aluno de Letras), mais experiente, que já atuou como interagente em processos prévios de interação em teletandem. As sessões de mediação visam à autoavaliação e à reflexão compartilhada e mediada pelo professor acerca: (a) do processo de colaboração, de reciprocidade e de aprendizagem entre os parceiros e (b) dos conteúdos das conversas durante a interação (informações linguísticas e culturais). Frequentemente, perguntas deflagradoras de reflexão utilizadas pelo professor-mediador são: (a) O que você aprendeu na sessão de hoje, em termos de língua e de cultura? (b) Que informações linguísticas e culturais vocês trataram na sessão de hoje? Que diferenças foram encontradas e de quais modos elas foram tratadas? Com relação ao uso que você faz da língua-alvo, como você se sentiu na primeira sessão de teletandem e nesta última?

De acordo com o que foi exposto, o desenvolvimento profissional de professores no contexto do Projeto Teletandem Brasil é visto como uma construção compartilhada de conhecimentos entre os professores em formação inicial (no caso, alunos de Letras - Línguas Estrangeiras que realizam sessões de teletandem) e os professores-mediadores (VIEIRAABRAHÃO, 2007).

No caso deste trabalho o professor-mediador foi um professor universitário. Ele assume o papel de "coformador" dos (futuros) professores de línguas, juntamente com a universidade. A ele cabe levantar reflexões acerca do processo de ensino e da aprendizagem intandem, nas sessões de mediação com os interagentes. O mediador é, também, visto como um formador em formação, no trabalho conjunto com os interagentes e nas demais atividades do projeto do teletandem.

$\mathrm{O}$ aluno-professor tem como suas primeiras concepções aquelas construídas como aprendiz de LE, sobre as quais ele refletirá criticamente, a partir do contato com teorias e práticas pedagógicas (ver ABRAHÃO, 2011). Com a reflexão sobre sua prática docente compartilhada com um par mais experiente, o licenciando em Letras é capaz de construir suas próprias teorias e redimensionar aquelas adquiridas anteriormente, de 
acordo com as necessidades e características de cada contexto, ao invés de ser um mero implementador de teorias prontas.

Em se tratando da aprendizagem de línguas por meio do teletandem, no qual aprendizes brasileiros de línguas estrangeiras interagem com aprendizes de outros países interessados em aprender a língua portuguesa, o ensino de português como língua estrangeira (doravante PLE) torna-se bastante relevante, já que, em muitos momentos, o interagente brasileiro adquire a posição de tentar explicar sua própria língua e cultura ao interagente estrangeiro.

Tendo em vista a representação significativa do Brasil no cenário econômico mundial e, consequentemente, o crescente interesse dos estrangeiros em aprender o português, há cada vez mais a necessidade de se formarem profissionais capacitados para atuar em contextos de ensino de PLE. A bibliografia sobre o assunto ainda é pequena e merece ser desenvolvida. Este trabalho traz, entre os seus objetivos, a discussão de aspectos relacionados à formação do professor de PLE para ensino da língua à distância. Esperamos suscitar questões importantes para o atual cenário de ensino de PLE nos contextos educacionais brasileiros, sejam eles presenciais ou à distância.

De acordo com Almeida Filho (2007), ensinar PLE inclui "estudar os processos de ensinar e aprender PLE em distintos e específicos contextos" (p. 34). O professor de PLE deve se equipar de conhecimentos sobre o próprio processo de ensino e aprendizagem de LE, sobre a natureza da língua e sobre a cultura na qual a língua está inserida.

Além de discutir questões gerais sobre o uso do contexto do teletandem para o ensino e aprendizagem de línguas, julgamos necessário a seleção de um aspecto específico a ser analisado no desenvolvimento da proficiência linguística do aprendiz da língua estrangeira: o enfoque na forma. Entendemos como enfoque na forma uma noção que extrapola o tradicional foco na forma, tal como é definido por SPADA (1997), "um esforço pedagógico para chamar a atenção do aluno a focalizar a estrutura linguística de maneira implícita ou explícita" (p. 73). O enfoque na forma pressupõe "um ensino que integra forma e significado dentro de um contexto comunicativo" (LONG, 1991). Observamos que a atenção à forma na interação selecionada para análise neste trabalho envolve não apenas o focalizar a estrutura da língua no nível morfossintático, mas também o enfoque no significado, ao tratar do léxico da língua dentro de determinadas estruturas linguísticas. $\mathrm{O}$ enfoque, portanto, significa a ação 
do professor de oferecer correções ou reestruturação da fala do aprendiz, que pode recair sobre a morfossintaxe, o léxico ou a pronúncia da língua.

O enfoque na forma é visto aqui como parte do processo de ensino e importante para que o aprendiz desenvolva um nível mais elevado de proficiência na LE. Sendo assim, o professor deve ser preparado para ensinar e tratar das formas da língua durante a interação com os alunos, principalmente quando o objetivo é melhorar o nível de proficiência destes, o qual se refere aos domínios de linguagem necessários para comunicação em diversos contextos. Proficiência pode, então, ser entendida como a demonstração concreta da competência linguísticocomunicativa do falante em contextos específicos de uso da língua (SCARAMUCCI, 2000). A competência linguístico-comunicativa e pedagógica do professor permitirá que ele aja de uma maneira ou de outra, de acordo com as especificidades da situação e do contexto.

A interação de teletandem selecionada para análise neste trabalho é parte do banco de dados do projeto "Teletandem Brasil: Línguas estrangeiras para todos" (TELLES, 2006; 2009; TELLES; VASSALLO, 2006). Trata-se de uma interação com duração de 52 minutos, que foi gravada em áudio e vídeo e, subsequentemente, transcrita. Os interagentes são uma estudante de Letras de uma universidade pública brasileira e um estudante de relações internacionais de uma universidade de um país anglofalante. Embora os dados selecionados para este trabalho sejam apenas uma pequena amostra do tipo de interação que acontece no teletandem, acreditamos que este estudo possa contribuir para reflexões iniciais sobre a natureza dos episódios com enfoque na forma e sobre a formação do professor de LE.

Feitas as colocações iniciais, os objetivos deste estudo são:

(a) verificar os modos pelos quais os episódios com enfoque na forma podem contribuir para a competência linguístico-comunicativa do aprendiz (interagente estrangeiro);

(b) observar como a interagente brasileira, participante deste estudo, lida com os momentos de enfoque na forma.

\section{O Projeto Teletandem Brasil}

O Projeto Teletandem Brasil: Línguas Estrangeiras para Todos foi financiado pela Fundação de Amparo à Pesquisa do Estado de São 
Paulo (FAPESP) como projeto temático ${ }^{1}$ que realiza pesquisas de iniciação científica, mestrado e doutorado da Universidade Estadual Paulista (UNESP), desde 2006. Possui um grupo de pesquisa certificado pelo Conselho Nacional de Desenvolvimento Científico e Tecnológico (CNPq). ${ }^{2}$ As pesquisas envolvem dados de interações entre estudantes brasileiros e estrangeiros falantes de diferentes línguas estrangeiras, de diversas universidades no mundo. ${ }^{3}$

O contato entre os alunos é estabelecido pela equipe coordenadora do projeto, composta por docentes dos departamentos de línguas estrangeiras dos campi da UNESP de Assis e São José do Rio Preto, e por docentes dos departamentos de português das universidades estrangeiras. As interações são supervisionadas pelos docentes das instituições parceiras e por pesquisadores, alunos de pós-graduação da UNESP, os quais atuam como mediadores do trabalho dos interagentes. As interações ocorrem de forma síncrona por meio do uso de ferramentas de comunicação online, como Skype e MSN, que permitem aos aprendizes interagir por meio da escrita, da fala e de suas próprias imagens por meio de webcams. Essa multimodalidade proporciona o desenvolvimento das habilidades orais, escritas e paralinguísticas dos interagentes.

O papel dos mediadores é importante, principalmente para que os interagentes brasileiros, estudantes do curso de Letras, possam refletir criticamente acerca do processo de ensino e aprendizagem de línguas e desenvolver as competências necessárias para atuarem como professores de LE.

Entre as ações do projeto Teletandem Brasil está a formação de professores-mediadores para o uso do teletandem. Com o grande número de pesquisas realizadas no escopo do projeto e de pesquisadores envolvidos, conta-se, atualmente, com um número significativo de especialistas que podem atuar como mediadores e multiplicadores da aprendizagem em teletandem (FUNO, 2011). Até o momento da redação deste trabalho, o projeto expandia o uso do teletandem como contexto de aprendizagem colaborativa online de línguas estrangeiras entre

\footnotetext{
${ }^{1}$ Ver $<$ http://www.bv.fapesp.br/pt/auxilios/1222/teletandem-brasil-linguas-estrangeiraspara-todos $>$.

${ }^{2}$ Ver $<$ http://dgp.cnpq.br/buscaoperacional/detalhegrupo.jsp?grupo=0330801NX9IQZT $>$. ${ }^{3}$ Informações sobre o projeto e a produção científica resultante dele podem ser encontradas no site <www.teletandembrasil.org $>$.
} 
adolescentes e professores, brasileiros e americanos, das redes públicas de educação dos respectivos países.

Uma sessão regular de teletandem é composta de três fases básicas: (1) conversação sobre um ou mais tópicos; (2) feedback linguístico; e (3) reflexão compartilhada sobre a sessão (TELLES; VASSALLO, 2006).

A aprendizagem de línguas in-tandem acontece a partir da interação colaborativa e da ajuda recíproca entre pares de falantes nativos de diferentes línguas de modo que um possa aprender a língua do outro e ensinar sua língua materna (ou de proficiência). Em alguns casos, o teletandem é realizado entre parceiros, falantes de duas línguas diferentes, que desejam praticar uma terceira, como língua franca; por exemplo, um italiano e um brasileiro que praticam e se comunicam em inglês como língua franca.

As interações via teletandem permitem aos aprendizes trocas linguísticas, culturais, sociais e profissionais.

São três os princípios fundamentais da aprendizagem in-tandem: bilinguismo, reciprocidade e autonomia (TELLES; VASSALLO, 2006). $\mathrm{O}$ bilinguismo refere-se à divisão da sessão de interação em duas partes, cada uma delas dedicada a uma língua, de modo que os interagentes sejam desafiados a usar a língua que estão aprendendo. A reciprocidade está relacionada ao princípio "o que faço para você, espero que faça o mesmo para mim". Tal princípio favorece a troca de conhecimento linguístico e cultural entre os interagentes. Esse princípio também inclui procedimentos de feedback que os interagentes podem receber do seu parceiro sobre seu desempenho na interação. A autonomia, por sua vez, refere-se à responsabilidade, ao comprometimento e ao poder de decisão dos interagentes acerca de seus processos de aprendizagem, ou seja, a liberdade de escolha de conteúdos e objetivos da interação, aprendizagem "autodirigida" (TELLES, 2006; 2009; CAVALARI, 2009).

Neste trabalho, o teletandem é visto mais especificamente como um contexto interacional e multimodal online (escrita, leitura pelo chat, produção e compreensão oral pelos recursos de voz e imagens, por meio da webcam). Quando os próprios professores de línguas estrangeiras praticam o teletandem, esse contexto pode contribuir para a formação do professor de línguas no sentido de desenvolver suas habilidades linguísticas e interculturais para, futuramente, no caso do aluno de Letras, atuar como mediador de um processo colaborativo de ensino e aprendizagem de seus alunos. Conforme afirma Kaneoya (2008, p. 
234), a construção da prática docente em teletandem é marcada pela ressignificação do sentido de ensinar línguas. Nesse contexto, cada interagente é responsável por ajudar o outro a aprender.

A colaboração e a reciprocidade entre os interagentes de teletandem são concretizadas na tomada de decisões sobre as metas e gerenciamento da aprendizagem, tais como assuntos a serem tratados, maneiras e momentos de se fazer correção sobre os usos linguísticos, tipos de mídia a serem utilizados como subsídios para as interações.

\section{0 enfoque na forma}

De uma perspectiva interacionista, a conversação em LE é fonte de informações sobre a língua que está sendo aprendida. É na interação que o aprendiz percebe o que pode ou não fazer na língua-alvo, além de praticar e testar suas próprias hipóteses sobre as formas e os usos da língua (GASS; MACKEY, 2006 apud BELL, 2012; SANTOS, 2008). Não obstante, de uma perspectiva sociocultural, a aprendizagem ocorre na interação e não como um resultado dela. A colaboração entre os aprendizes promove oportunidades para que eles alcancem além daquilo que fariam se estivessem sozinhos.

A partir da abordagem sociocultural, Swain (2000), em uma extensão da sua Hipótese da Produção (Output Hypothesis), propõe que a aprendizagem de línguas acontece no diálogo colaborativo. Assim, a atenção na produção individual passa para a produção dialógica interativa. É no diálogo colaborativo que os aprendizes co-constroem o conhecimento sobre a língua e resolvem problemas linguísticos (SWAIN; BROOKS; TOCALLI-BELLER, 2002).

A interação permite que o aprendiz relacione forma e significado mais facilmente, uma vez que a produção significativa do diálogo espontâneo (com temas escolhidos pelos próprios parceiros do teletandem) o envolve em processos cognitivos necessários para a consolidação das conexões forma-significado.

A conversação focada exclusivamente no significado não promove o desenvolvimento de um nível de proficiência linguística alto no que concerne especialmente à precisão gramatical (SWAIN, 1985). Por isso, o enfoque na forma é importante na interação e permite que o aprendiz note as diferenças entre sua produção linguística e a produção de falantes mais proficientes. 
Tradicionalmente, os episódios linguísticos ${ }^{4} \operatorname{com}$ foco na forma são definidos como partes de um diálogo em que os aprendizes falam sobre a língua que estão produzindo, questionam o seu uso, ou corrigem a si mesmos ou a outros (SWAIN; LAPKIN, 1998). O conceito pode ser utilizado em pesquisas em sala de aula de línguas para identificar a frequência e a maneira como os aprendizes lidam com características problemáticas da língua-alvo. Elas podem ser do tipo gramatical, ortográfico, semântico ou até mesmo fonológico em situações de interação oral entre aprendizes.

O foco na forma pode ser planejado ou incidental (ELLIS, 2001). As atividades de foco na forma planejado são aquelas desenvolvidas de modo a conscientizar o aprendiz sobre formas pré-selecionadas da língua. Já o foco na forma incidental refere-se à atenção espontânea para a forma que aparece durante as atividades focadas no significado. Um exemplo de foco na forma incidental acontece quando um aprendiz questiona a pronúncia de uma palavra na LE durante a conversação. Além disso, estudos mostram que esse tipo de foco na forma aparece mais em atividades centradas no significado do que em atividades mecânicas (SANTOS, 2008; LEONE, 2012).

A noção de percepção consciente de aspectos linguísticos (noticing) (SCHMIDT; FROTA, 1986), juntamente com as considerações sobre o foco na forma levantadas nesta seção, parece alinhar-se à noção de enfoque na forma que buscamos. Para Schmidt (1990, 2001), não há aprendizagem sem que haja uma atenção consciente e focada no insumo linguístico. Assim, a percepção consciente de aspectos relacionados à morfossintaxe e à semântica da língua estrangeira é que permite ao aprendiz criar e confirmar hipóteses sobre o funcionamento da língua e usar as estruturas e o léxico da LE de maneira adequada.

\section{Discussão dos dados}

$\mathrm{Na}$ análise da interação, que é objeto deste estudo, foi feito primeiramente um levantamento das ocorrências de episódios com enfoque na forma. Consideraram-se como enfoque na forma momentos nos quais os interagentes estão tratando explicitamente de questões sintáticas, lexicais, morfológicas, semânticas, ortográficas ou fonológicas

${ }^{4}$ Language related episodes, em inglês. 
da língua portuguesa. Embora a interação de teletandem contenha uma parte na qual os interagentes conversam em inglês e outra parte na qual eles usam o português, o ponto central deste estudo está na formação do professor de PLE, como já foi dito. Por tal razão, serão analisados os momentos nos quais os interagentes se comunicam em português. Nosso objetivo é, portanto, observar como a interagente brasileira, aluna de graduação em Letras, futura professora de língua estrangeira, lida com o enfoque na forma.

$\mathrm{Na}$ interação de teletandem selecionada para este estudo, os casos de episódios com enfoque na forma são, em sua maioria, referentes às questões lexicais. Entre as 28 ocorrências de enfoque na forma identificadas, 25 foram classificadas nessa categoria. Apenas 2 ocorrências são de ordem gramatical (uso de forma verbal e uso de advérbio) e 1 ocorrência de ordem fonológica (pronúncia de palavra). Tal fato confirma afirmações anteriores (SANTOS, 2008) de que grande parte do insumo linguístico do teletandem está relacionada a itens lexicais, provavelmente pela centralidade das sessões de teletandem na comunicação e na discussão de conteúdos interculturais por meio de contrastes entre as duas culturas dos parceiros de teletandem.

No trecho abaixo, observa-se que Gabi, a interagente brasileira e professora em formação, fornece a palavra em português que Will, o interagente americano, busca dizer, mas não consegue. A dificuldade de Will em encontrar a palavra correta é vista por suas tentativas em espanhol e inglês, além do uso da expressão exclamativa "nossa". Gabi imediatamente diz a palavra "relação" em português e a escreve no chat. Will, então, repete a palavra em português corretamente e Gabi confirma dizendo "isso".

Excerto (1):

Will: $\quad$ Não... e quando... hum... aqui nos Estados Unidos quando eu hum... eu vi um brasileiro, quando eu escuto o português, imediatamente eu vou a... a pessoa e... chat... huh... não sei... falo um pouquinho sobre... com... com ele ou ela e huh... não, porque... eles... vocês... são tan... tão carinhosos, então eu quando... vocês... estão aqui, nos Estados Unidos, eu quero... huh... ser carinhoso também. E, então, é... é uma... uma maneira... para huh... compartir isso... huh... relación... relationship...

Gabi: Ressa! $\quad$ Rẹa! ! (escreve no chat)

Will: Relação, si.

Gabi: $\quad$ Isso. 
No segundo excerto, observa-se que Will utiliza a estratégia da tradução para dizer que assiste a aulas ou faz cursos para aprender mais sobre a cultura de outros países. Ele usa "toma cursos ou aulas" como equivalente a take courses na sua língua materna. Gabi faz uma correção explícita, dizendo que em português a frase é "assistir aulas" (no registro coloquial do português). Em seguida, ela faz uma pergunta ao seu parceiro, incluindo a frase "fazia algum curso", o que pode ser uma maneira de ela sinalizar, indiretamente (correção implícita), que no português utiliza-se também a frase "fazer cursos". Esse exemplo é capaz de suscitar a reflexão do professor sobre a correção da produção do aprendiz.

Excerto (2):

Will: acho que cada pessoa quer.. aprender um pouco mais... mas, no... não... trabalha para aprender, para entender outra pessoa. Eh.. então, não sei. Eu toma huh... cursos o aulas como isso, para aprender um pouco mais.

Gabi: Ah, entendi. A gente diz "assistir aulas».

Will: Assistir, assistir, sim.

Gabi: Mas antes de vir pro Brasil você já queria aprender português, você já fazia algum curso ou não? Foi só depois?

Ainda como uma forma de corrigir desvios na fala de Will, Gabi utiliza a reformulação como uma estratégia de correção. Sua reformulação é feita de maneira direta, em uma pergunta. Essa pergunta pode ser entendida como reformulação e/ou como uma maneira de esclarecer o que Will queria dizer, já que ele responde afirmativamente, confirmando a ideia que ele queria expressar. A pura reformulação poderia ocorrer ainda inserida em uma sentença mais completa, do tipo "você começou seu aprendizado".

Excerto (3):

Will: Agora, acho que a música é o meu... foi o meu... o minha coisa favorita de Brasil e foi como huh... a coisa que huh... comecei o meu... huh... aprendendo do português.

Gabi: Seu aprendizado?

Will: Sim, sim. 
O segundo exemplo de reformulação encontra-se no excerto (4). Nesse caso, Will apresenta um desvio fonológico ao pronunciar a palavra "antiga". Gabi responde à pergunta de Will, pronunciando a palavra da maneira correta, embora ele não demonstre se atentar para o desvio de pronúncia. Entende-se que, mesmo que Will não tenha direcionado sua atenção para a correção do seu desvio de pronúncia feito por Gabi, ainda assim houve a ocorrência de um episódio linguístico. Sendo assim, o episódio linguístico não será necessariamente compartilhado pelos interlocutores, uma vez que a intenção de reformulação da interagente brasileira, como falante mais competente do português, mantém-se.

\section{Excerto (4):}

Gabi: Sim. Ah, que legal! Então você tem um bom gosto musical. Eu gosto de tudo que você falou.

Will: $\quad \operatorname{Sim}$ (ri). Esse... (incompreensível).. é a música mais antigua, não? Ou mais huh....

Gabi: Mais antiga, sim!

Will: $\quad$ Mas, há outros como... você sabe As garotas suecas?

Há momentos em que Will busca a ajuda de sua parceira para produzir a palavra correta, como se pode ver nos excertos (5) e (6) a seguir. Nesse caso, Gabi funciona como um "andaime" ou suporte para a aprendizagem de Will, conforme a conceituação vygostkiana. Ela auxilia o parceiro a aprofundar sua compreensão das nuanças de sentido e de uso das palavras "engraçado" e "cômico". Gabi, como o membro do par mais competente da interação, fornece estruturas de apoio para que Will, o membro menos competente em português, atinja aquilo que está além das suas possibilidades individuais de produção.

Excerto (5):

Will: Muito mais fácil. Sim. Paulo, ou algo assim. Mas, quando no... na Argentina o meu huh... mãe de casa... como huh... eu... vivia como uma.... uma Argentina huh... o... Arge... uma mãe da Argentina. Huh... Então, ela huh... sempre... huh... me... me disse como: «Paul! Paul! (risos) como o meu nome no mal e foi um pouco... huh... não sei... cômico! Huh... Como se diz? En...

Gabi: Engraçado? (escreve no chat) 
Will: Engraçada, si.

Gabi: Isso. Engraçado (continua escrevendo)

Will: Engraçado.

Gabi: Mas, cômico está certo também (escreve cômico). Cômico.

Will: Ah, sim?

Gabi: Mas, a gente usa mais «engraçado».

Will: Engraçado é mais popular para dizer?

Gabi: Isso. É mais popular. «Cômico» não é todo mundo que entende.

Will: Ok. Si, sim...

Will demonstra conhecer que há um sinônimo para "cômico" em português e arrisca a usar a palavra "engraçado". Gabi imediatamente completa a palavra iniciada por ele e a escreve no chat. Ela ainda afirma que usar "cômico" é correto, no entanto "engraçado" é um uso mais frequente e popular entre os falantes de português. Em casos como esse, cabe ao professor de línguas considerar os usos e os contextos de uso dos registros linguísticos e explicitá-los aos aprendizes.

No excerto (6), novamente o interagente americano tenta encontrar a palavra adequada no português por meio do uso das línguas espanhola e inglesa e recorre à ajuda da sua parceira para chegar às palavras "mercearia" e "chefe". Gabi diz as palavras corretas e as escreve no chat, uma estratégia recorrente na sua prática nessa interação. Mais uma vez, ela atua como um "andaime" ao ajudar o outro, seu parceiro, a completar a tarefa, ou seja, a construção de uma mensagem em língua estrangeira.

Excerto (6):

Will: $\quad$ Sim, a faculdade... eu trabalho numa... numa... tienda? Huh... numa... huh... tienda de «grocery»? Como se diz «groceries»... Isso (escreve a palavra no chat)

Gabi: (repetindo o que lê) Grocery...

Will: $\quad$ Você sabe como?

Gabi: Eu acho, assim... eu acho que é uma mercearia (escreve no chat).

Will: Mercearia! Sim!

Gabi: Mercearia, é isso?

Will: Mercearia.

Gabi: Ah, você trabalha em uma mercearia? 
Will: $\quad$ Sim, mas é uma mercearia huh... de... qual... onde... cados... hum... cadas as trabalhadores são estudantes. Então, como eu... não s... eu não sou uma... como ... trabalhador básico eu... comos... eu sou huh... o... boss! Huh... como se diz isso? (rindo)

Gabi: $\quad$ O chefe! (rindo e escrevendo)

Will: $\quad$ O chefe (rindo). Sim.

Em alguns momentos, Will se arrisca a produzir palavras das quais ele não tem certeza. No excerto (7), ele utiliza "dançaroa" e "dançadora" para a palavra "dançarina". Gabi escreve a palavra correta no chat, mas dessa vez não a pronuncia.

No excerto (8), Gabi corrige a fala de Will com relação às palavras "madura" e "maturidade", uma vez que ele novamente se arrisca ao dizer "matureza". Nesse caso, Gabi interrompe Will para esclarecer o uso da palavra correta. Seu esclarecimento aparece em forma de exemplos contextualizados em sentenças de modo a mostrar a diferença em se dizer "madura" ou "maturidade".

Excerto (7):

Will: Sim... e se... você não huh... não quer... ser... uma huh... professora huh... depois, você pode trabalhar como uma dançaroa? Dançadora do ventre, não?

Gabi: (Escreve a palavra correta no chat - «dançarina») Ah, não!!! (ri)

Will: (Lendo o que ela escreveu no chat) Dançarina. (rindo)

Excerto (8):

Will: Mas, acho que... no Brasil, você é mais huh... matur... matureza? Você tem mais matureza? Porque... prá ser...

Gabi: $\quad$ Pera aí (escrevendo no chat). Ma... é mat... A gente diz «madura», «Você é mais madura» ou «Você tem maturidade.»

Will: Maturidade, si. Madura... huh... Não sei se é verdade, mas... parece que sim, às vezes.

$\mathrm{O}$ enfoque na forma aparece também quando há necessidade de se esclarecer o significado do que foi dito pelos interagentes ou por dificuldade de compreensão da parte de um deles. No excerto (9), 
a confusão se dá pela semelhança de grafia e pronúncia das palavras "anterior" e "interior". Gabi resolve a confusão enfatizando que disse "anterior", o que pode ser observado pelo uso das letras maiúsculas na transcrição da interação. Além disso, ela escreve a palavra no chat.

Excerto (9):

Gabi: Mas, eu voto, eu sempre voto. Eu gosto de fazer o meu dever. E... eu voto... voto na... o ano passado eu não votei porque eu não tava aqui, mas eu votei no Lula... nas outras eleições e eu apoio a Dilma, também. Porque... eu acho que... que a política deles é mais liberal... (parceiro anota o que ela diz) exatamente como você falou... (sorriso) Porque a política anterior, que era do PSDB, o outro partido.

Will: $\quad$ Sim... heh... a política do interior é distinto... huh... distinta ou muito diferente que a política das cidades?

Gabi: (Pausa) A política das cidades?

Will: $\quad$ O... I... você... huh... dize que... a política do interior... do país é um pouco mais...

Gabi: Ah, não, não!!! A política ANTERIOR (escrevendo a palavra no chat).

Will: Oh, anterior..., ANterior...

Gabi: $\quad$ Isso! (pausa) E... o outro, o outro presidente, antes do Lula.

Will: Ah, sim.

Há ainda ocorrências nas quais as explicações sobre itens lexicais são mais detalhadas, como acontecem nos excertos (10) e (11).

No excerto (10), a partir da incompreensão da palavra "quietinho" por Will, Gabi procura utilizar a metalinguagem e a tradução em inglês para explicar a formação da palavra. Will apresenta dificuldades em pronunciar a palavra corretamente, por isso Gabi escreve a palavra no chat várias vezes.

Excerto (10):

Gabi: Você tem cara de ser super quietinho.

Will: Cara copotino?

Gabi: (escrevendo) Quietinho.

Will: Quietino.

Gabi: Quietinho... Isso. Very quiet.

Will: Ah, sim? 
Gabi: Sim. Você conhece... é... é o que só trabalha e vai para a faculdade. (...) Ou não? (ri)

Will: (Rindo) Quietinho? E o que significa «quinentinha»?

Gabi: Quietinha? Huh... (escrevendo no chat) Quiet? Mas é...

Will: $\quad$ Si, sim. Então...

Gabi: Então, é quietinho. A palavra é quieto (escrevendo no chat).

Will: Quieto (escrevendo)

Gabi: Isso. Quietinho é... «little quiet».

Will: Ok, ok (ri). Sim, sim. Eu acho que sim.

No excerto (11), Gabi e Will falam sobre a falta de tempo em função de suas atividades na faculdade. Gabi fala, então, sobre o estágio que deve fazer para a sua formação como professora. Will desconhece o significado da palavra "estágio" e Gabi explica. Logo em seguida, Will tem dúvida sobre como usar o advérbio "também", equivalente a either para dizer que sua parceira também não tem muito tempo livre. Gabi apenas diz que "também" equivale a either ou neither, mas não fornece exemplos, o que poderia facilitar o entendimento do seu parceiro e enriquecer seu vocabulário e conhecimento de estruturas da língua portuguesa.

Excerto (11):

Gabi: Também. Eu... eu dou aula, né? Mas.... Eh...O problema é que as minhas aulas são estágio... você entende «estágio»?

Will: «Estágio»? Não.

Gabi: Estágio... (escrevendo no chat) Hum... Quando a gente faz faculdade, no meu curso, aqui no Brasil, de Letras... a gente precisa trabalhar, assim, dar aulas, assim, é obrigatório, faz parte da faculdade, pra aprender.

Will: Ok, ok.

Gabi: Entendeu? Então, eu comecei a dar aula o ano passado, mas agora, é porque é obrigatório. Eu estudo... de manhã e trabalho à tarde, dou aula à tarde.

Will: Ah... então, sim, você não tem muito tempo a ninguém ou huh... «neither»... huh... sim, você não tem...

Gabi: Não. Também (escrevendo). Huh huh... Também (escrevendo no chat). Também pode ser «neither» ou «either»-também. Tanto na negativa como na afirmativa.

Will: Ah, é ambos, não?

Gabi: Ambos. Sim (sorri). Não, também não tenho muito tempo. 
O excerto (12) mostra uma única ocorrência na qual Gabi, para sanar a dúvida de Will sobre a frase "falta de emprego", recorre à consulta da tradução da frase para o inglês e não procura explicar o seu significado utilizando a própria língua portuguesa.

Excerto (12):

Gabi: E o que mudou, assim? Os... os problemas dos Estados são só em... são as empregos... a falta de emprego, ou não? O que mudou na sua vida?

Will: $\quad$ Falta de emprego?

Gabi: Hum... (procura no Google Translator e encontra) Un... Unploy... Unply... (riso embaraçado porque não consegue

Will: Oh!

Gabi: (Sorrindo) Sorry!

Will: Não não não não! Izo é uma... problema muito grande.. hum...mas... acho que também... hum... nossas huh... nos poli... nossos políticos não están hum... fazendo cada coisa que... que podem

Por fim, o excerto (13) corresponde ao enfoque na forma referente a um aspecto gramatical. Nesse exemplo, Will apresenta dificuldade em encontrar a forma do pretérito imperfeito do verbo "ter". Gabi, ao perceber a hesitação de Will para dizer o verbo na forma correta, a fornece de maneira oral e escrita.

Excerto (13):

Will: Huh... (pausa para pensar) ainda assim. Mas... ele... huh... não sei. Não sei se eu tenho a confianza muito que... que... huh... tim... tiv... que eu... (tentando achar a forma verbal).

Gabi: que você TINHA! (escreve no chat).

Will: $\quad$ Sim! Tinha... huh... ao passado... no passado... sim, sim.

\section{Conclusões sobre a análise dos dados}

Pela descrição dos episódios com enfoque na forma nessa interação, pode-se interpretar que a alta recorrência de episódios em que há o tratamento do léxico da língua portuguesa se dá em função de algumas limitações de conhecimento da LE do aprendiz. Will apresenta um bom nível de proficiência em português, já que ele consegue conduzir 
uma conversa na língua-alvo e falar sobre diversos assuntos. No entanto, ele ainda precisa da mediação de sua parceira para produzir o vocabulário adequado em alguns momentos. A aquisição de vocabulário permanece um ponto a ser constantemente desenvolvido, mesmo quando o aprendiz já possui conhecimento das estruturas básicas da língua estrangeira.

Assim como foi demonstrado no estudo de Williams (1999), os dados deste trabalho mostram que o enfoque na forma iniciado espontaneamente pelo aprendiz referente ao léxico e ao significado é muito mais recorrente do que qualquer outro aspecto da língua. Nas interações de teletandem analisadas neste estudo, o enfoque na forma é incidental, uma vez que as dúvidas sobre e as dificuldades na LE emergem do próprio uso da língua estrangeira para a comunicação. Nesse caso, a atenção às formas da língua não é previamente definida pelos interagentes. No caso da interação deste estudo, a análise dos dados revela que o enfoque sobre a forma se deu, principalmente, em nível lexical. Tentamos elencar pelo menos quatorze ações colaborativas entre os parceiros pelas quais se dá esse enfoque. Nesses casos, o parceiro:

- fornece uma palavra da língua-alvo ao outro;

- escreve as palavras novas no chat;

- fornece tradução de uma palavra desconhecida para explicar sua formação, consulta e discute a tradução com o parceiro mais proficiente;

- faz correções explícitas e implícitas;

- usa a reformulação como estratégia de correção;

- retifica, de maneira explícita ou implícita, a pronúncia de uma palavra pronunciada incorretamente;

- busca a ajuda do parceiro de teletandem para produzir a palavra correta;

- auxilia o parceiro a aprofundar sua compreensão das nuanças de sentido e de uso das palavras de sua língua;

- completa a palavra iniciada pelo parceiro e a escreve no chat;

- considera os usos e os contextos de usos dos registros linguísticos e os explicita;

- tenta encontrar a palavra adequada com a ajuda do parceiro;

- esclarece ao parceiro o uso da palavra de modo correto, 
padrão ou não padrão;

- fornece exemplos contextualizados em sentenças, para mostrar as diferenças entre formas e palavras e esclarecer o significado do que foi dito;

- utiliza a metalinguagem para explicar a formação da palavra.

No que concerne à formação do professor, depreende-se, então, que o professor de LE precisa estar preparado para lidar com a metalinguagem na língua-alvo e com as estratégias necessárias para o tratamento do léxico. Além disso, a partir desses dados, verifica-se que ao professor cabe, também, refletir sobre as maneiras adequadas de fazer a correção da produção do aluno.

Do ponto de vista interacional, nota-se que o teletandem, por ser um contexto no qual os aprendizes utilizam a LE para conversar livremente sobre diferentes assuntos, permite identificar as reais necessidades do aprendiz e as maneiras adequadas de lidar com tais necessidades. $\mathrm{O}$ resultado é a potencialização desse contexto de aprendizagem para o desenvolvimento da competência linguístico-comunicativa do aprendiz, a partir da conscientização da relação entre forma e significado (desenvolvimento sintático e semântico) e da negociação de significados, o que é inerente a qualquer contexto comunicacional.

\section{Implicações para os cursos de formação de professores de línguas}

No curso de Licenciatura em Letras, o teletandem pode ser uma ferramenta auxiliar na formação do futuro professor de línguas para atuar nos novos contextos de ensino e aprendizagem de línguas, instaurados pelo uso das novas tecnologias, principalmente da internet. A participação dos alunos (professores em formação) em interações de teletandem como parte constituinte das aulas de prática de ensino permite que estes reflitam sobre sua prática docente diante das novas realidades dos contextos de ensino à distância e sobre as competências que lhes são necessárias para a atuação nesses contextos. Assim, além de terem a chance de melhorar seus níveis de proficiência na língua estrangeira que vão ensinar, os futuros professores constroem sua própria prática.

A partir da descrição de uma interação de teletandem feita neste trabalho, observa-se a importância de se estudarem e discutirem 
as maneiras de fazer a correção da produção do aluno e o impacto da correção para o aprendizado, avaliando-se os resultados obtidos. Esse seria um aspecto a ser tratado nas sessões de mediação, nas quais os professores em formação interagem com profissionais mais experientes tanto na língua-alvo quanto na prática de ensino da mesma.

O enfoque na forma também merece atenção nas sessões de mediação. Nelas, podem ser criados contextos reflexivos e colaborativos nos quais os professores em formação possam refletir sobre como e em quais momentos fazer explicitações sobre a língua-alvo, a partir de exemplos retirados das interações. O enfoque na forma e a reflexão sobre o seu uso no processo de ensino e aprendizagem de LE podem contribuir para o desenvolvimento da competência metalinguística dos professores. Isso porque o domínio da terminologia e da metalinguagem dos conteúdos a serem ensinados constitui uma das habilidades específicas do professor de línguas, juntamente com a competência discursiva para o tratamento dos conteúdos da língua.

A capacidade do professor de LE de falar sobre a forma e o uso da língua é um dos aspectos definidores do domínio específico de uso da língua para esse profissional, segundo Elder (1994) e Martins (2005). Não obstante, ele deve ter a capacidade para produzir insumo estruturado e adequado na língua-alvo e modificá-lo sempre que necessário, de modo a ser compreensível ao aprendiz.

A formação do professor de línguas deve buscar a interação entre conhecimento teórico e conhecimento prático. A construção pessoal da prática pedagógica de cada um se dá, além de outras maneiras, pelas oportunidades de o futuro professor ter "explicitado para si próprio suas concepções sobre linguagem, ensinar e aprender" (VIEIRA-ABRAHÃO, 2004), proporcionadas por suas experiências relevantes como aprendiz e como professor.

\section{Considerações finais}

Neste trabalho, foram discutidas questões relacionadas ao ensino e à aprendizagem de línguas via teletandem, do ponto de vista da formação do professor de LE e do desenvolvimento da competência linguísticocomunicativa dos interagentes. Buscou-se traçar considerações sobre a realidade imposta pelo uso das novas tecnologias no ensino de línguas estrangeiras e as consequências para a formação didática e linguística dos futuros professores. 
A análise proposta pautou-se na descrição dos episódios com enfoque na forma da língua portuguesa. Na interação selecionada para este estudo, pudemos observar o prevalecimento do enfoque na forma referente ao tratamento do léxico por meio de, pelo menos, 14 ações colaborativas entre os pares que propiciam momentos de explicitação sobre o vocabulário do português. São momentos nos quais a interagente brasileira auxilia seu parceiro na produção da palavra adequada, seja fornecendo a palavra correta, elucidando significado, estabelecendo distinções e nuanças de significados, seja corrigindo os desvios de vocabulário do interagente americano (momentos em que o interagente americano utiliza vocábulos considerados inadequados pela interagente brasileira). A presença da correção dos desvios levou à discussão da necessidade de refletir sobre esse aspecto nas sessões de mediação no teletandem e, de maneira mais ampla, na formação do professor de línguas.

As experiências com o teletandem possibilitam a reflexão do futuro professor a respeito do que faz nesse novo contexto de aprendizagem de línguas. A mediação, por sua vez, leva interagentes e mediadores a trabalharem em colaboração para sua emancipação profissional, de modo a atuarem seja em contextos de ensino de línguas presenciais, seja à distância.

Há duas limitações importantes deste nosso estudo a serem, por fim, consideradas. A primeira diz respeito ao fato de termos focado nossa análise somente nos dados de uma interação entre uma brasileira e um americano e não, também, o reverso, já que estávamos tratando de colaboração online entre parceiros. A segunda limitação diz respeito ao fato de mencionarmos a importância das sessões sobre mediação sem trazermos dados sobre elas. Embora desejássemos ter trazido ambos os dados para análise, por questões de espaço, optamos pelos recortes que aqui apresentamos para tratar da complexidade do tema. No entanto, acreditamos que, na primeira limitação, o exemplo trazido para análise (entre uma brasileira e um americano) ainda apresenta, de modo satisfatório e provocador, os fenômenos que optamos por focar neste artigo. Certamente, não desejando encerrar as questões aqui apresentadas com apenas um artigo, procuramos abrir espaço para futuros estudos acerca do reverso (o americano interagindo com a brasileira) e dos fenômenos inerentes às sessões de mediação constantes na base de dados do projeto Teletandem Brasil. Ambas as limitações, porém, são aqui apontadas para consideração de nossos leitores. 


\section{Referências}

ABRAHÃO, M. H. V. Uso da tecnologia na formação inicial do professor de línguas no Projeto Teletandem Brasil - Línguas estrangeiras para todos. In: BARCELOS, A. M. F. (Org.). Linguística Aplicada: reflexões sobre ensino e aprendizagem de língua materna e língua estrangeira. Campinas: Pontes, 2011.

ALMEIDA FILHO, J. C. P. Maneiras de credenciar-se na área de ensino de português a falantes de outras línguas. In: ALMEIDA FILHO, J. C. P.; CUNHA, M. J. C. (Org.). Projetos iniciais em português para falantes de outras línguas. Campinas, Pontes: 2007. p. 33-37.

BELL, N. Comparing Playful and Nonplayful Incidental Attention to Form. Language Learning, v. 62, n. 1, p. 236-265, 2012.

BELZ, J. A. Social Dimensions of Telecollaborative Language Study. Language Learning and Technology, v. 6, n. 1, p. 60-81, 2002.

BRAGA, D. B. Práticas letradas digitais: considerações sobre possibilidades de ensino e de reflexão social crítica. In: ARAÚJO, J. C. (Org.). Internet \& ensino: novos gêneros, outros desafios. Rio de Janeiro: Lucerna, 2007.

BRASIL. Ministério da Educação. Diretrizes curriculares nacionais para a formação de professores de educação básica. Brasília (DF): Conselho Nacional de Educação, 2002.

BRASIL. Ministério da Educação. Resolução CNE/CP n ${ }^{\circ} 1$, de 18 de fevereiro de 2002. Disponível em: http://portal.mec.gov.br/seesp/ arquivos/pdf/res1_2.pdf. Acesso em: 29 abr. 2013.

CANDIDO, J. Sessões de orientação e suas perspectivas para o curso de Letras. 2010. 230 f. Dissertação (Mestrado em Estudos Linguísticos) Universidade Estadual Paulista, São José do Rio Preto, 2010. Disponível em: <http://www.teletandembrasil.org/site/docs/CANDIDO.pdf $>$. Acesso em: 9 jan. 2015.

CAVALARI, S. M. S. A auto-avaliação em um contexto de ensinoaprendizagem de línguas em tandem via chat. 2009. $269 \mathrm{f}$. Tese (Doutorado em Estudos Linguísticos) - Universidade Estadual Paulista, São José do

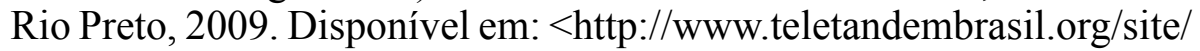
docs/SPATI.pdf>. Acesso em: 9 jan. 2015.

ELDER, C. Performance Testing as a Benchmark for LOTE Teacher Education. Melbourne Papers in Language Testing, v. 3, n. 1, p. 1-25, 1994. 
ELLIS, R. Investigating Form-focused Instruction. Language Learning, v. 51, suppl. 1, p. 1-46, 2001.

FUNO, L. B. A. Teletandem e formação contínua de professores vinculados à rede pública de ensino do interior paulista: um estudo de caso. 2011. 195 f. Dissertação (Mestrado em Estudos Linguísticos) Universidade Estadual Paulista, São José do Rio Preto, 2011. Disponível em: <http://base.repositorio.unesp.br/bitstream/handle/11449/93894/ funo_lba_me_sjrp.pdf?sequence=1>. Acesso em: 9 jan. 2015 .

KANEOYA, M. L. C. K. A formação inicial de professoras de línguas para/em contexto mediado pelo computador (teletandem): um diálogo entre crenças, discurso e reflexão profissional. Tese (Doutorado em Estudos Linguísticos) - Universidade Estadual Paulista, São José do Rio Preto, 2008.

LEONE, P. Leadership in Multimodal Computer-mediated Second Language Communication for Reciprocal Learning. Journal of E-Learning and Knowledge Society, v. 8, n. 3, p. 55-66, 2012. Disponível em: $<$ http://services.economia.unitn.it/ojs/index.php/Je-LKS_EN/article/ viewFile/642/641>. Acesso em: 29 nov. 2013.

LONG, M. Focus on Form: A Design Feature in Language Teaching Methodology. In: DEBOT, K.; GINSBERG, R.; KRAMSCH, C. (Ed.). Foreign Language Research in Cross-cultural Perspective. Amsterdam: John Benjamins, 1991.

MARTINS, T. H. B. Subsídios para a elaboração de um exame de proficiência para professores de inglês. 2005. 115 f. Dissertação (Mestrado em Linguística Aplicada) - Instituto de Estudos da Linguagem, Universidade Estadual de Campinas, Campinas, 2005.

SANTOS, G. R. Características da interação no contexto de aprendizagem in-tandem. 2008. 197 f. Dissertação (Mestrado em Estudos Linguísticos) - Universidade Estadual Paulista, São José do Rio Preto, 2008. Disponível em: <http://www.teletandembrasil.org/site/docs/ DissertacaoGersonRossi.pdf $>$. Acesso em: 9 jan. 2015.

SCARAMUCCI, M. Proficiência em LE: considerações terminológicas e conceituais. Trabalhos em Linguística Aplicada, Campinas, v. 36, n. 11, p. 11-22, 2000. 
SCHMIDT, R. The Role of Consciousness in Second Language Learning. Applied Linguistics, n. 11, p. 129-158, 1990.

SCHMIDT, R. Attention. In: ROBINSON, P. (Ed.). Cognition and Second Language Instruction. Cambridge(UK): Cambridge University Press, 2001.

SCHMIDT, R.; FROTA, S. Developing Basic Conversational Ability in a Second Language: A Case Study of an Adult Learner of Portuguese. In: DAY, R. (Ed.). Talking to Learn: Conversation in Second Language Learning. Rowley: Newbury House, 1986.

SONTAG, D. M. A Learning Theory for 21st Century Students. Disponível em: <http://www.editlib.org/d/104246>. Acesso em: 9 jan. 2015.

SPADA, N. Form-focussed Instruction and Second Language Acquisition: A Review of Classroom and Laboratory Research. Language Teaching, v. 30, p. 73-87, 1997.

SWAIN, M. Communicative Competence: Some Roles of Comprehensible Input and Comprehensible Output in its Development. In: GASS, S.; MADDEN, C. (Ed.). Input in Second Language Acquisition. Rowley: Newbury House, 1985. p. 235-253.

SWAIN, M. The Output Hypothesis and Beyond: Mediating Acquisition through Collaborative Dialogue. In: LANTOLF, J. P. (Ed.). Sociocultural Theory and Second Language Learning. Oxford (UK): Oxford University Press, 2000.

SWAIN, M.; BROOKS, L.; TOCALLI-BELLER, A. Peer-peer Dialogue as a Means of Second Language Learning. Annual Review of Applied Linguistics, n. 22, p. 171-185, 2002.

SWAIN, M.; LAPKIN, S. Interaction and Second Language Learning: Two Adolescent French Immersion Students Working Together. Modern Language Journal, v. 82, n. 3, p. 320-337, 1998.

TELLES, J. A. Teletandem Brasil: línguas estrangeiras para todos. Projeto apresentado ao CNPQ nº 061/2005 (Seleção pública de projetos de pesquisa nas áreas de Ciências Humanas, Sociais e Sociais Aplicadas). Faculdade de Ciências e Letras, Departamento de Educação, Universidade Estadual Paulista, Assis, 2006.

TELLES, J. A. Teletandem: um contexto virtual, autônomo e colaborativo para a aprendizagem de línguas estrangeiras do século XXI. Campinas: Pontes, 2009. 
TELLES, J. A.; VASSALLO, M. L. Foreign Language Learning In-tandem: Teletandem as an Alternative Proposal in CALLT. The ESPecialist, v. 27, n. 22, p. 189-212, 2006.

VIEIRA-ABRAHÃO, M. H. Crenças, pressupostos e conhecimentos de alunos-professores de língua estrangeira e sua formação inicial. In: VIEIRA-ABRAHÃO, M. H. (Org.). Prática de ensino de língua estrangeira: experiências e reflexões. Campinas: Pontes/ArteLíngua, 2004.

VIEIRA-ABRAHÃO, M. H. A formação inicial e continuada do professor no Teletandem Brasil: línguas estrangeiras para todos. CONFERENCIA INTERNACIONAL DE EDUCACIÓNA DISTANCIA, 2007, Monterrey. Anais... Monterrey: Instituto Tecnológico de Monterrey, 2007.

WILLIAMS, J. Learner-generated Attention to Form. Language Learning, v. 49, suppl. s1, p. 583-625, 1999. 
